\title{
sciendo
}

\author{
RESEARCH PAPERS FACULTY OF MATERIALS \\ SCIENCE AND TECHNOLOGY IN TRNAVA \\ SLOVAK UNIVERSITY OF TECHNOLOGY \\ IN BRATISLAVA
}

2019, Volume 27, Number 45

DOI 10.2478/rput-2019-0021

\section{PROPOSAL OF AN ALGORITHM FOR DATA COLLECTION AND PROCESSING VIA RFID TECHNOLOGY}

\author{
Marek VAGAŠ${ }^{1}$, Alena GALAJDOVÁ ${ }^{1}$, Dušan ŠIMŠÍK ${ }^{1}$, Ivan CVITIĆ ${ }^{2}$ \\ ${ }^{1}$ TeCHNiCAL University OF KoŠICE, FACUlTy OF MECHANICAL ENGINEERING \\ Institute OF AUtOMATION, MECHATRONICS, RoBOtics AND PRODUCTION SYSTEMS \\ DEPARTMENT OF AUTOMATION AND HUMAN MACHINE INTERACTIONS \\ LETNÁ 9, 04200 KoŠICE, SLOVAK REPUBLIK \\ e-mail:marek.vagas@tuke.sk, alena.galajdova@tuke.sk,dusan.simsik@tuke.sk \\ ${ }^{2}$ UNIVERSITY OF ZAGREB, FACULTY OF TRANSPORT AND TRAFFIC SCIENCES \\ TRG MARSALA TITA 14, HR-10000 ZAGREB, CROATIA \\ e-mail: ivan.cvitic@fpz.hr \\ Received 29 August 2018, accepted 23 September 2019, published 29 November 2019
}

\begin{abstract}
With incoming Industry 4.0 implementation, RFID technology is becoming one of the main part for (not only) automotive industry, as a source to identify any inconsistencies or failures in automated processes. Its implementation in the automated workplaces is conditioned by the real-time data collection depending on workflows and increasing demands for processing, and publishing of these data. As such, RFID technology enables the real-time data integration from objects as well as from people or inventory management, asset management and monitoring, alarm collection and evaluation, predictive maintenance, and overall critical digital communications.
\end{abstract}

\section{Key words}

RFID technology, automated workplace, algorithm, data processing

\section{INTRODUCTION}

Radio Frequency Identification Technology (RFID) is a wireless communication technology that allows users to uniquely identify objects by using electromagnetic waves. Automated workplaces capable for collecting, transmitting, and evaluating information help us to improve various aspects of information processes and increase the level of automation as one of the key points for greater deployment of Industry 4.0 and efficiency of automated operations as such [1]. One of the most common reasons for implementing RFID in Slovakia is traceability of goods (or products). Another, though less specific, reason is to gain a competitive advantage. On a larger scale, use of technology can be enforced by either the manufacturer or the vendor, but is currently considered too expensive. This modern technology is not yet sufficiently widely 
used in Slovakia and there is no indication so far that this technology is massively introduced in e.g. logistics. However, testing projects keep continuously increasing in various other industry areas [2].

The main reason is the cost of implemented technology being, weak of competitive pressure, ignorance of managers who do not trust the new developed technologies. The RFID system consists of the RFID tags consisting of a microchip with an antenna and a reader with an antenna [3]. The reading device emits electromagnetic waves to which the marker antenna is tuned. For passive RFID tags, the field thus generated are used to power the microchip circuitry; for active RFID tags, energy is obtained from battery power. The microchip then generates waves that the tag sends back to the reader, which converts them into digital form. The principle of RFID technology is shown in Figure 1.

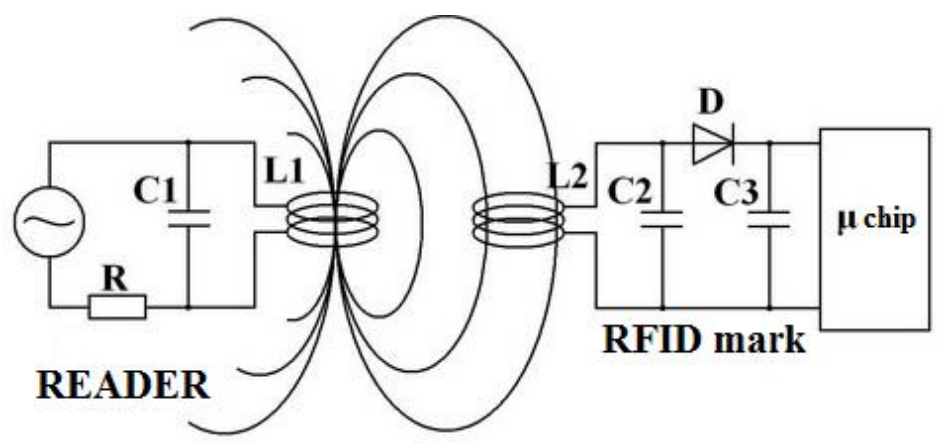

Figure 1 Principle of RFID technology [2]

The RFID technology brings several advantages:

- automatic data collection without human intervention,

- chip for identification can be placed invisibly and still be legible,

- accurate, unambiguous marking and thus traceability of each single piece in industry,

- interconnection of chips with sensors.

\section{ISO standard}

Owing to different techniques of using contactless cards from different manufacturers, it was necessary to develop standardisation. Currently, three standards are being used (ISO/IEC 14443, ISO/IES 10536, and ISO/IEC 15693). Each of these standards includes multiple technical solutions. Terminals must be compatible with all capabilities offered by the standard [4].

\section{ISO/IEC 14443}

ISO/IEC 14443 Standard, in original: "Identification cards - Contactless integrated circuit(s) cards - Proximity cards", describes properties of contactless chip cards. It contains four parts:

- Part 1: Physical properties,

- Part 2: Radio frequency sourcing and signal interfaces,

- Part 3: Initializing and anti-collision techniques,

- Part 4: Transmission protocols. 


\section{ISO/IEC 10536}

ISO/IEC 10536 Standard describes the cards with close bonds, in original: "Identification Cards - Contactless Integrated Circuit(s) Cards". Applications under this standard are referred to as a slot or surface operation, which indicates that cards must be inserted into the slot or used on the card reader when in use. The Standard consists of:

- Part 1: Physical characteristics,

- Part 2: Dimensions and location of linked areas,

- Part 3: Electronic signals and procedure reset,

- Part 4: Answer to reset and transmission protocols.

\section{ISO/IEC 15693}

The Standard in original "Identification cards - Contactless integrated circuit(s) cards Vicinity cards", describes properties and working modes of contactless cards with range from 1 to $1.5 \mathrm{~m}$. Systems according to this standard operate on the frequency of $13.56 \mathrm{MHz}$. This type of card is used preferentially in applications where there is no need for contactless card to be in the hands of user, it can remain in the wallet, purse, etc. However, this Standard has not yet found a widespread use in the smart card systems [5].

\section{METHODOLOGY}

Application of methodologies for deploying the RFID technology to automated workplaces depends mainly on whether these investments bring savings to businesses and businesses in other areas as well. This applies to tracking stocks in warehouses as well as tracking other data necessary for better process planning [6]. Since this technology uses radio waves that are influenced by many factors (environmental impact, interference, reflections from obstacles, absorption, bending...), the principles of amplitude modulation and demodulation used in RFID need to be known, see Figure 2.

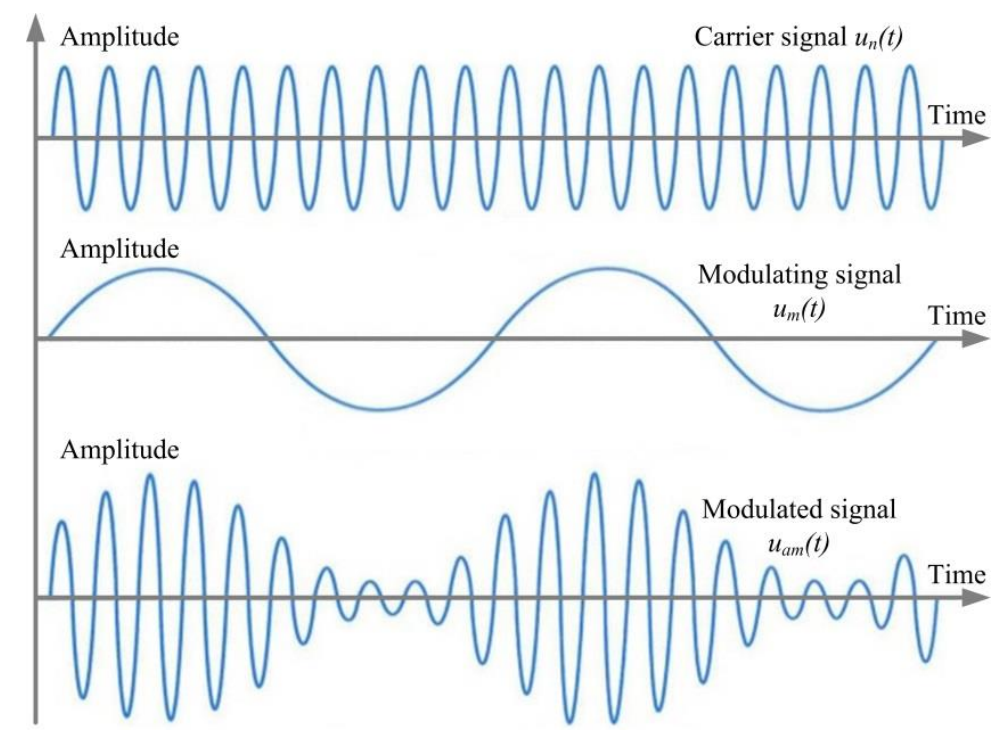

Figure 2 Transformation of magnetic field to the data 
Carrier signal with amplitude $\mathrm{u}_{n}$ and carrier frequency $\omega_{n}$ can be determined as:

$$
u_{n}(t)=U_{n} \times \cos \left(\omega_{n} t\right) .
$$

Modulating signal with amplitude $\mathrm{u}_{m}$ and frequency $\Omega$ can be determined as:

$$
u_{m}(t)=U_{m} \times \cos (\Omega t) .
$$

Amplitude modulation is generated by adding $u_{m}(t)$ to the amplitude of carrier signal. By substitution to the equations, we get a relation for modulated signal:

$$
u_{a m}(t)=\left(U_{n}+U_{m} \times \cos (\Omega t) \times \cos \left(\omega_{n} t\right) .\right.
$$

After multiplying, we get:

$$
u_{a m}(t)=U_{n} \times \cos \left(\omega_{n} t\right)+U_{m} \times \cos \left(\omega_{n} t\right) \times \cos (\Omega t) .
$$

The combination of two trigonometric functions with different arguments is divided by the relationship:

$$
\cos x \times \cos y=\frac{1}{2}[\cos (x-y)+\cos (x+y)] .
$$

We get an expression in which it is easy to see that modulated signal consists of one carrier, a sum and a difference band:

$$
\left.\left.u_{a m}(t)=U_{n} \times \cos \left(\omega_{n} t\right)+\frac{1}{2} U_{m} \times \cos \left(\omega_{n}-\Omega\right) t\right)+\frac{1}{2} U_{m} \times \cos \left(\omega_{n}+\Omega\right) t\right) .
$$

The course of amplitude modulation can be described by the relationship:

$$
u_{a m}(t)=U_{n}\left(1+m \times \cos (\Omega t) \times \cos \left(\omega_{n} t\right)\right) .
$$

Coefficient $m$ represents the amplitude modulation index and applies:

$$
m=\frac{u_{m}}{u_{n}}
$$

If we express the amplitude modulation factor in percentage, we get modulation depth am:

$$
m=\frac{u_{m}}{u_{n}} \times 100 \% \quad[\%]
$$

Demodulation is a process by which we get back a low-frequency modulation signal from a modulated high-frequency signal (modulated data from an RFID tag in our case). We divide the amplitude demodulation into asynchronous and synchronous. For proper operation of demodulator, an RC member must have a suitably dimensioned time constant $\tau$. For $\tau=\mathrm{RC}$ in the condition:

$$
\frac{1}{\Omega_{\max }} \gg \tau \gg \frac{1}{\omega_{n}}
$$


where $\Omega_{\max }$ is max of modulation signal frequency and $\omega_{n}$ is frequency of carrier signal. When we consider a harmonically modulating signal $f_{m}(t)$ and frequency $\Omega$, so at the input of demodulator, we get the following voltage:

$$
S_{a m}(t)=u_{n}\left(1+m f_{m}(t)\right) \times \cos \left(\omega_{n} t\right)
$$

If a reference signal is available in the form:

$$
u_{r}(t)=u_{r} \times \cos \left(\omega_{n} t\right)
$$

after multiplying, we get:

$$
\begin{aligned}
& u_{a m}(t) \times u_{r}(t)=u_{n} \times u_{r} \times\left[\frac{1+\cos \left(2 \omega_{n} t\right)}{2}+\frac{m}{4} \times \cos \left(2 \omega_{n} t-\Omega t\right)+\frac{m}{4} \times \cos \left(2 \omega_{n} t+\right.\right. \\
& \left.\Omega t)+\frac{m}{2} \times \cos (\Omega t)\right] .
\end{aligned}
$$

One-way component $\frac{u_{n} \times u_{r}}{2}$ and demodulated signal component $\frac{m \times u_{n} \times u_{r} \times \cos (\Omega t)}{2}$ will be filtered out by a lower pass filter.

In synchronous demodulation, input signal may show a significantly lower level, which positively affects stability. Another advantage of synchronous demodulation is better linearity and a more favourable signal/noise ratio. The lack of synchronous demodulation requires a reference carrier wave and greater circumferential complexity [7].

\section{DESIGN}

Wireless data collection from automated workplaces will use the Arduino-based algorithm. The designed algorithm serves as a tool for collecting and organizing product information, orders, statuses, or other workplace data, see Figure 3. 


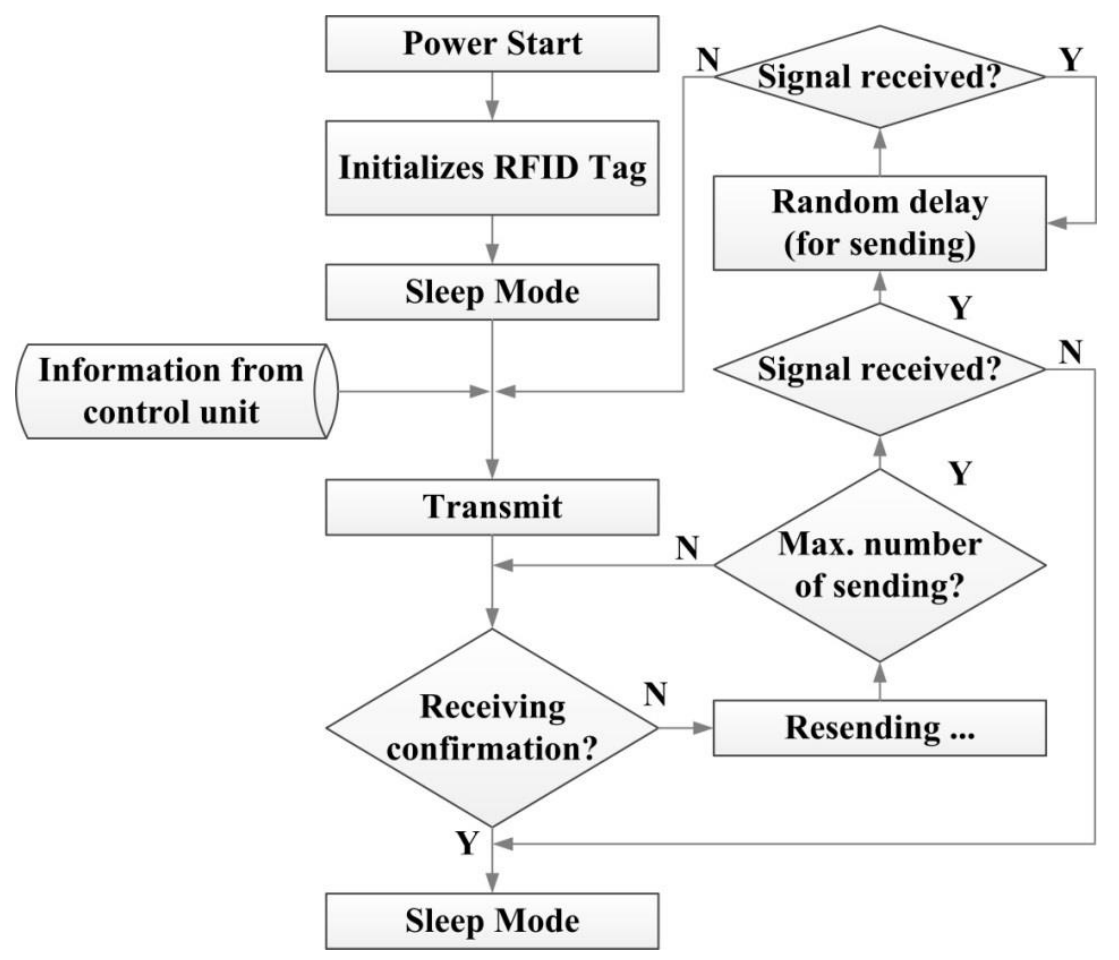

Figure 3 Proposed algorithms for communication

Reader can detect easily a tag in its range. The distance is the critical parameter in power consumption. When a tag is absent, a lot of power losses occur, which due to the constant process of powering-up the component blocks of the reader, for example the demodulator and RF generator. This is basically a standard, as the typical system tries to read/detect the tag. Another way to minimize the energy consumption is optimizing the data volume to be transmitted, signal processing in the RFID tag, and the percentage of time the embedded RFID tag is on by using the sleep/awake protocol algorithm. The embedded RFID tag is battery powered, and therefore requires power efficient hardware and a minimum amount of signal processing [8].

Processing of data collection is based on the database usage with Visual Basic interface. The database serves as a tool for collecting and organizing the product information, orders, statuses, or other workplace data. Visual Basic provides a simple graphical customization with options to create various icons, objects, and any customizations [9]. After creating the environment in each section, we can assign an action program to the icon. Programming in this environment is generally considered to be the best choice, especially for easy publishing of the designed program. Visual Basic can work with Excel, MySQL and other databases. Many databases start as a list in a word processor or as a table. When the list is expanding, data becomes redundant and inconsistent.

\section{CONCLUSION}

Proposed RFID algorithm in combination with appropriate devices and sufficient financial resources enables a full-featured tracking of objects at selected automated workplaces. Note, that the more automation progresses, the more likely it is to implement some form of tracking. Especially, when deploying a greater range of automation in workplaces, ability to manually track on-going processes or applications to track something going on in these processes is reduced. This is particularly evident in the robotized workplaces where one has no access to safety. 


\section{Acknowledgement}

This paper was supported by the Slovak Grant Agency VEGA 1/0330/19 - Research and design of algorithms and systems for the fusion of heterogeneous data in multisensor architectures.

\section{References}

[1] PÁLENÍK, T. 2007. Princípy prenosu informácií v RFID systémoch (Principles of information transfer in RFID systems). AT\&P Journal, Vol. 9, pp. 26-27. ISSN 1335-2237

[2] LUKÁŠEK, P. 2008. Systémy automatickej identifikácie (Systems of automated identification). In: Portál pre odborné publikovanie (Portal for specialised publications), Študentské publikovanie. Elektrotechnika. Posterus. ISSN 1338-0087

[3] KOUR, R., KARIM, R., PARIDA, A., \& KUMAR, U. 2014. Applications of radio frequency identification (RFID) technology with eMaintenance cloud for railway system. International Journal of System Assurance Engineering Management, 5(1), 99-106.

[4] DAVID, J. 2013. Príklady použitia systémov RFID Turck. (Examples of RFID Turck systems.) Automa Journal, Snimače a merici technika (Sensors and measuring technology), Vol. 5. p. 36. ISSN 1210-9592

[5] HUBA, M., KOZÁK, Š. 2016. From e-learning to Industry 4.0. In: ICETA 2016. Danvers: IEEE, s. 103-108. ISBN 978-1-5090-4699-7

[6] LIN, M., ROWAIHY, H., BOLBROCK, T., CAO, G. and PORTA, T. L. Data Collection Using RFID and a Mobile Reader. In: IEEE Global Telecommunications Conference. New Orleans, LO: IEEE GLOBECOM, pp. 1-6.

[7] PETRÍK, M. 2010. Modul pre rádiofrekvenčnú identifikáciu (RFID) (Module for radio-frequence identification). Bachelor thesis. Bratislava: STU, FEI, Department of radioelectronics.

[8] Dargie, Waltenegus. (2012). Dynamic Power Management in Wireless Sensor Networks: Stateof-the-Art. IEEE Sensors Journal - IEEE SENS J. 12. 1518-1528. DOI:10.1109/JSEN.2011.2174149.

[9] ONOFREJOVÁ, D., ŠIMŠÍK, D. 2017. Výskumné aktivity zamerané na budovanie platformy pre priemysel 4.0 (Research activities focused on building a platform for 4.0 Industry.) In: ATP Journal. No. 4, pp. 36-38. ISSN 1335-2237

\section{ORCID}

Marek Vagaš 0000-0002-8660-8484 